\title{
SOBRE UM ROSTO - UM ROSTO
}

\section{Diego Cervelin}

Mestrando em Literatura - UFSC
RESUMO: Esse texto procura desdobrar algumas considerações a respeito da percepção da imagem do rosto da personagem Lóri, do livro Uma aprendizagem ou o livro dos prazeres, publicado por Clarice Lispector em 1969. Para isso, serão estudados os dispositivos políticos que envolvem a apreensão do rosto como uma qualificadora do sujeito e, ao mesmo tempo, a sua relação com a linguagem.

PALAVRAS-CHAVE: Rosto; Política; Linguagem

ABOUT A FACE - A FACE

ABSTRACT: This text intents to unfold some considerations regardind the perception of the image of the Lori's face, from the book Uma aprendizagem ou o livro dos prazeres, published by Clarice Lispector in 1969. For that, will be studied the politicians devices who involve the apprehension of the face as a qualifying of the subject and, at the same time, its relation with the lenguage.

KEY-WORDS: Face; Politics; Lenguage 
O que acontece quando os olhos observam a imagem de um rosto sobre a superfície de um espelho? Os olhos observam um "retrato" daquilo que a pessoa inexoravelmente é ? Os olhos são capazes de perceber a "facticidade" da existência de um rosto? Para tentar desdobrar essas questões, tomaremos como exemplo um dos momentos de Uma aprendizagem ou o livro dos prazeres, livro escrito por Clarice Lispector, em 1969. Mais especificamente, falaremos da cena em que Lóri, personagem narradora do livro e professora ginasial, decidiu ir ao salão de bailes onde se realizava o encontro promovido pela escola em que trabalhava. Pois bem, sentindo-se um tanto quanto insegura por ir desacompanhada ao evento, Lóri carregou o rosto de maquiagem a ponto de sentir-se uma estranha: "pintou demais os olhos e demais a boca até que seu rosto branco de pó parecia uma máscara: ela estava pondo sobre si mesma alguém outro: esse alguém era fantasticamente desinibido, era vaidoso, tinha orgulho de si mesmo. Esse alguém era exatamente o que ela não era" (LISPECTOR, 1998, p. 83). E, ainda que o desconforto de suportar o reflexo da espessa camada de pó e ungüentos colada à pele fosse tão grande a ponto de causar vertigens, a personagem nos diz que "sem pintura seria a nudez da alma" (LISPECTOR, 1998, p. 84).

Ora, um rosto a observar-se diante do espelho é um dos temas mais recorrentes tanto na arte quanto na filosofia do Ocidente. Durante o século XVII, por exemplo, podia falar-se dessa reflexão no sentido de uma moralizadora vanitas vanitarum. Tratava-se do rosto que, mundanamente bem nutrido e apresentado como reflexo do fausto da vida em movimento, em última análise, estava tão-somente a um passo da fria e descarnada caveira. Daí podiam partir as mais variadas imprecações religiosas sobre a comiseração humana, as ladainhas dos atos institucionalmente apreendidos. Isso porque se a carne não se podia manter eternamente pulsante, algo haveria de rumar para um além dos túmulos: fosse a alma que, nos braços do Cristo, encontrasse o leu alento ou a obra do homem que, disposta como monumento, se preservasse para as gerações vindouras. Essas foram algumas formas que pretenderam resolver de modo definitivo, ainda que especialmente no âmbito simbólico, a caducidade e a efemeridade da condição humana sobre a terra. Abria-se, assim, o espaço tanto para a conformação de unidade no corpo místico do Cristo quanto para a manifestação teológico-política de um outro corpo unitário, já secularizado, o Estado. Ambas as soluções dependiam de uma medida de poder e autoridade que reunisse os elementos dispersos do mundo enquanto unidades - o que não deixa de desdobrar, in nuce, o surgimento do "eu" moderno, criatura orgulhosa de uma pretensa completude de si. (É interessante observar que, 
também no século XVII, o pintor Michelangelo Merisi da Caravaggio, ao representar Narciso pouco antes de cair no mergulho mortífero sobre a própria imagem, já poderia expor uma espécie de enunciado alegórico sobre os riscos de compreender a observação da imagem como reflexão ontologizante da realidade.)

Girando justamente em torno da apresentação deste "eu”, poderíamos pensar em algumas perguntas que virtualmente restaram inarticuladas na boca de Lóri. Como suportar o olhar perfurante dos outros? Será que eles perceberão a vertigem que perpassa aquele que é observado? Conforme aponta Giorgio Agamben no texto L'Io, l'occhio, la voce, publicado em 1980 como apresentação à tradução italiana do Monsieur Teste, de Paul Valéry, a presença ao olhar teria desempenhado um dos papéis mais relevantes para a constituição da metafísica ocidental enquanto problematização da essência, da natureza e dos fins do homem. Tratava-se, nesse sentido, de como pensar e procurar resolver - a existência do homem em relação aos outros. Mas aí também estava presente uma tentativa de permitir que aquele que se olha e é olhado pudesse reconhecer-se como um ser uno e individual, o "eu", contando com a capacidade de confrontar-se com o mundo. Tal estratagema de reconhecimento, nas palavras do filósofo italiano, se desenvolveu tanto como pensamento da presença da alma a si mesma quanto das coisas existentes à alma. Ou seja, aí estava em jogo a idéia de que pode dar-se uma unidade humana intimamente relacionada tanto com a possibilidade da presença ao olhar - o olho que se reconhece imediatamente no espelho - quanto com a presença à consciência - o discurso referindo-se imediatamente, através do pronome “eu”, à voz daquele que o pronuncia (AGAMBEN, 2005a, p. 97).

Ainda nesse mesmo ensaio, Giorgio Agamben retoma alguns aspectos do experimento descrito pelo filósofo do século XVII René Descartes no quinto capítulo do estudo sobre a dióptrica. Ali o interesse do filósofo francês se dispunha a comprovar que todo ato de visão se apresenta como um juízo intelectual do sujeito pensante (AGAMBEN, 2005a, p. 97). Nesse sentido, não haveria possibilidade de falar-se de uma visão concreta, mas somente de um ego cogito me videre - eu penso ver - na condição de reflexão do "eu" a partir dos rastros de sinais sensíveis reconhecíveis no fundo dos olhos. Por outro lado, tal qual aponta a leitura de Agamben, a imagem do homem que observa esse processo de visão reflexiva, tal qual utilizada por Descartes para ilustrar seu pensamento, operaria por uma duplicação irônica em que o olho que vê se transformaria no mesmo instante em olho visto. E isso de tal sorte que a visão não poderia ser apresentada senão como um ver-se vendo, "in una rappresentazione nel 
senso filosofico, ma anche nel senso teatrale del termine" (AGAMBEN, 2005a, p. 93).

Não é por menos que Lóri se sinta absolutamente devassada pelo olhar do taxista, já na saída do salão de bailes. Também a sua apresentação comporta uma dose teatral, uma máscara de teatro, a persona, que, além disso e ao mesmo tempo, denomina o sujeito:

O modo como o chofer olhou-a fê-la adivinhar: ela estava tão pintada que ele provavelmente tomara-a como uma prostituta. "Persona" [...] Também Lóri usava a máscara de palhaço da pintura excessiva. Aquela mesma que nos partos da adolescência se escolhia para não se ficar desnudo para o resto da luta. Não, não é que se fizesse mal em deixar o próprio rosto exposto à sensibilidade. Mas é que esse rosto que estivesse nu poderia, ao ferir-se, fechar-se sozinho em súbita máscara involuntária e terrível: era pois menos perigoso escolher, antes que isso fatalmente acontecesse, escolher sozinha ser uma "persona". Escolher a própria máscara era o primeiro gesto voluntário humano. E solitário. Mas quando enfim se afivelava a máscara daquilo que se escolhera para representar-se e representar o mundo, o corpo ganhava uma nova firmeza, a cabeça podia às vezes se manter altiva como a de quem superou um obstáculo: a pessoa era (LISPECTOR, 1998, pp. 85-86).

Se, como nos diz Lóri, a escolha da persona é o primeiro gesto voluntário humano, vale observar que isso não acontece para um simples deleite daquele que desempenha o ato de escolher. A escolha da máscara serve para dar à existência uma nova firmeza diante do mundo, diante das outras personae. Muito oportunamente, Gilles Deleuze e Félix Guattari, no ensaio sobre a rostidade publicado em Mil Platôs, nos apresentam o rosto como elemento que envolve uma política (DELEUZE \& GUATTARI, 2007, p. 50). O rosto estaria disposto a uma estratégia de poder que opera através da máquina abstrata de rostidade. Ou seja, pela tentativa maquínica de formação de unidades de rosto, "de um rosto elementar em correlação biunívoca com um outro" (DELEUZE \& GUATTARI, 2007, p. 44) capaz de permitir a seleção e a identificação dos rostos concretos em termos de "x ou y", de pertencimento ou exclusão em uma determinada ordem. Mas, para que isso fosse possível, em primeiro lugar, a máquina abstrata não poderia considerar a cabeça como sendo ela mesma o rosto:

A cabeça está compreendida no corpo, mas não o rosto. O rosto é uma superfície [...] o rosto é um mapa [...] Mesmo humana, a cabeça não é forçosamente um rosto. $\mathrm{O}$ rosto só se produz quando a cabeça deixa de fazer parte do corpo, quando pára de ser codificada pelo corpo, quando ela mesma pára de ter um código corporal polívoco multidimensional - quando o corpo, incluindo a cabeça, se encontra 
descodificado e dever ser sobrecodificado por algo que denominamos Rosto (DELEUZE \& GUATTARI, 2007, p. 35).

Por outro lado, a relação entre a cabeça e a tentativa de elevar o homem à condição de criador destinado a ocupar o espaço deixado por Deus foi analisada por Jean-Luc Nancy em um trecho do livro La créacion du monde ou la mondialisation. Ali o filósofo nos diz que a cabeça, para poder ser considerada como entidade soberana - e, dessa forma, autora da ordem do mundo secular à qual os corpos deveriam se submeter -, precisa estar separada do corpo. Ou seja, ela precisa elevar-se a um estágio em que somente ela ocupe o espaço de maior sumidade e superioridade, separada e para além do corpo, dos corpos, como superanu (NANCY, 2003, p. 95). É nesse sentido que se pode pensar na qualificação de um rosto como sendo sempre um ato de criação que, para definir-se, precisa utilizar uma dose de teatralidade. Ainda cabe lembrar que a soberania tal qual estudada pelo jurista alemão Carl Schmitt, na esteira do pensamento hobbesiano, se propunha a estabelecer (de)cisões capazes de apresentar critérios para o pertencimento ou não de determinados sujeitos no grande corpo virtual, teatral, do Estado-Nação. Estão em jogo nada mais nada menos do que as possibilidades de articulação das identificações e suas relações com a manutenção do poder constituído em uma ordem de governo na catástrofe ou na iminência dela (SCHMITT, 2006, p. 13).

Como apontaram as pesquisas de Giorgio Agamben a respeito do Homo sacer, o nexo que permite pensar a constituição de um corpo político unitário repousa na relação entre a soberania e a vida no horizonte da oikonomia das populações. Ao pautarse pela constituição política enquanto decisão binária de pertencimento ou exclusão, a relação soberana e seus desdobramentos sobre os corpos viventes, preocupando-se em arranjar a existência conjunta dos homens e a definição mesma daquilo que seja o homem, opera pela captura, na ordem do dizível, de um exterior - ex capere (AGAMBEN, 2002a, p. 25). Trata-se do estabelecimento da ordem e dos parâmetros capazes de promover as diferenças com base na decisão sobre o caso de exceção, ou seja, daquilo que se decide previamente como necessidade de diferenciação entre aquilo que pode ser dito normal daquilo que se qualifica como desviante: "a necessidade age aqui como justificativa para uma transgressão em um caso específico por meio de uma exceção" (AGAMBEN, 2004, pp. 40-41). Na medida em que, colocando-se no papel de soberano, o homem procura criar as situações "necessárias" para a vigência de um padrão de normalidade, Agamben pode nos falar da ordem e da unidade pretendida pelo 
corpo político também na condição de desenvolvimento de uma ficção - uma teatralidade, portanto - que encontra nos corpos viventes o seu ponto de apoio (AGAMBEN, 2004, p. 92). Aí a vida, sendo qualificada pelas instâncias de poder e servindo, ao mesmo tempo, de fundamento e destinatário da disposição política, permite a emergência da biopolítica - cujo reverso simétrico e relacional não é nada menos do que a tanatopolítica. Trata-se não menos de um pensamento em que está presente a tentativa de orientar a vida dos homens para um ideal que fosse capaz de sublimar, mais uma vez, a condição mortal a ponto de praticamente reduzir tudo aquilo que existe em termos de identidade e de representação.

Também Gilles Deleuze e Félix Guattari podem nos oferecer alguns elementos capazes de remeter ao processo que envolve a formulação do "eu" reconhecível no espelho como não estando distante da articulação de uma política voltada para a mera vida. $\mathrm{O}$ ponto de aproximação se apresenta quando nos dizem que a máquina abstrata de rostidade rejeita tanto os rostos não-conformes quanto aqueles que tenham ares suspeitos (DELEUZE \& GUATTARI, 2007, p. 44). Diante de uma articulação do poder, ninguém permanece sem rosto, mesmo o desvio precisa ser rostificado para, dessa maneira, ser devidamente tratado - capturado através da inclusão daquilo que se exclui. Nesse sentido, cruzando a argumentação de Deleuze em suas considerações sobre a disseminação da vigilância no Post-scriptum sobre as sociedades de controle e as análises desenvolvidas por Foucault no curso posteriormente publicado sob o título Segurança, território, população, também passa a ser possível pensar o deslocamento de uma sociedade disciplinar - que pretende criar a ordem e excluir a figura desviante para uma sociedade de controle - que, já a despeito do estabelecimento da lei imutável a ser cumprida erga omnes, pretende administrar preponderantemente as desordens, incluindo em cálculos prévios a própria desviança. No espaço do controle, o direcionamento do poder precisa ser recriado e rearticulado - diga-se de passagem, reencenado - a cada instante e de modo a sempre permitir novas formas de captura. Aí já não se pode falar que cada pessoa tem $o$ seu rosto de modo definitivo. Mas, ainda assim, as operações de rostificação permanecem atuantes e se disseminam, "pois será necessário produzir sucessivamente desvios padrão de desviança para tudo aquilo que escapa às correlações biunívocas, e instaurar relações binárias entre o que não é aceito em uma primeira escolha e o que não é tolerado em uma segunda, em uma terceira, etc" (DELEUZE \& GUATTARI, 2007, p. 45). 
É no horizonte dessas considerações que a reflexão do rosto de Lóri no olhar do taxista, já na condição de persona, pode apontar para outros caminhos. A máscara em contato com o rosto nu de Lóri, e que toma o seu lugar, recebe um nome, é qualificada ou seja, rostificada e capturada na linguagem - como sendo provavelmente o de uma prostituta. $\mathrm{O}$ rosto como emergência de um interior filtrado pela consciência, o rosto como expressão mais viva do interior da pessoa, que se apresenta como uma janela para a alma - é disso que nos fala grande parte da metafísica do homem no ocidente. No entanto, os estudos de Agamben em Quel che resta di Auschwitz nos permitem pensar o homem mais como um lugar de operações atravessado por processos de subjetivação e de dessubjetivação do que em uma completude que se abre naquela presença ao olhar capaz de ser assumida como propriedade. O pensamento sobre a essência ou natureza do homem, na medida em que procura incessantemente materializar os sujeitos a que se destina, opera preponderantemente como uma tentativa de domesticar e dispor dos viventes $^{1}$. Tal tarefa, no espaço da biopolítica contemporânea, desbordou o pensamento da noção de indivíduo e instalou-se na esfera dos poderes médico e jurídico, voltados para as massas, onde a existência do indivíduo é cada vez mais dividual (DELEUZE, 2006a, p. 222) Daí o atual apego ao saber médico que, sedimentado nas estatísticas da população, tanto se esmera na promoção de pesquisas sobre os limites da vida corporal ("animal"), situação refletida e reverberante na ordem daquilo que pode ser dito como normal. Daí surgem mais algumas questões. Quando alguém pode ser destinatário dos movimentos do poder? Quando e como pode ser dito um sujeito? Por outro lado, sabendo que, na qualidade de pensamento do controle dos desastres e das desordens, o poder não se pode restringir à configuração de uma ordem imutável, Agamben trata de nos apresentar os mecanismos mesmos que possibilitam tal deslocamento. Nesse sentido, os estudos do filósofo italiano apontam para a relação entre a potência e o ato que Aristóteles relegou ao pensamento no Ocidente. Eis que em Idea del potere, Agamben retoma algumas das considerações apresentadas pelo filósofo grego na Ética a Nicômaco a respeito do prazer e da dor: o prazer seria aquilo cuja forma se resolve a cada instante e, dessa forma, está sempre em ato; a potência, por sua vez, seria o contrário do prazer na medida em que, nunca estando em ato, faltaria sempre ao seu fim - a dor. Mas mesmo que toda a dor da potência pudesse desaparecer no momento em

\footnotetext{
${ }^{1}$ Cf. SLOTERDIJK, Peter. Regras para o parque humano. Tradução de José Oscar de Almeida Marques. São Paulo: Estação Liberdade, 2000, p. 17.
} 
que ela se transformasse em ato, nem toda a potência se esgota completamente em ato. Sobre isso Agamben nos diz que

esistono ovunque - anche dentro di noi - delle forze che costringono la potenza a attardarsi in se stessa. Su queste forze si fonda il potere: esso è l'isolamento della potenza dal suo atto, l'organizzazione della potenza. Raccogliendone il dolore, il potere fonda su questo la propria autorità: esso lascia letteralmente incompiuto il piacere degli uomini (AGAMBEN, 2002b, p. 51).

A qualificação "prostituta" utilizada por Lóri quando confrontada ao olhar alheio, imputando-se ao seu próprio rosto, parece ser um atravessamento desse tipo de forças - do poder. Podemos dizer, de outro modo, que o adjetivo utilizado nesse momento, além de seu tom reflexivo, poderia colocar Lóri em uma situação de abertura a uma série de imprecações de ordem exterior. Lóri estaria sujeita a uma disposição do poder. Nesse sentido, as qualificações, as identificações dos rostos são exemplos daqueles mecanismos de controle e organização que Agamben denomina dispositivos. A linguagem também desempenha esse mesmo papel ${ }^{2}$. Observe-se, então, que Lóri apenas suporta a persona "prostituta". Aí a familiaridade do rosto de Lóri se encontra em um ponto de estranhamento em que é dita como "prostituta". Em um dos fragmentos que Agamben publicou em La comunità che viene, expõe-se o pensamento de que uma esfera de poder é capaz de capturar os viventes somente quando eles assumirem uma identidade ou forem identificados (AGAMBEN, 2007, p. 69). A personagem de Clarice Lispector, longe de ter suas particularidades enclausuradas desde as primeiras páginas do livro, não é tão somente o indivíduo Lóri. Isso quer dizer que ela já não serve como exemplo de uma individualidade ou de um psiquismo a ser revelado. Lóri está antes para um encadeamento processual de trânsito de singularidade do que para uma identidade clara e definível - daí a possibilidade de ler-se o sintagma "uma aprendizagem" como um dos percursos possíveis entre subjetivação e dessubjetivação e não como mera apreensão da essência ou natureza humana.

\footnotetext{
2 O termo "dispositivo" é originário do grego oikonomia, que foi posteriormente traduzido para o latim como dispositio. O dispositivo, segundo Agamben, é "qualquer coisa que tenha de algum modo a capacidade de capturar, orientar, determinar, interceptar, modelar, controlar e assegurar os gestos, as condutas, as opiniões e os discursos dos seres viventes" (AGAMBEN, 2005b, p. 13). Além disso, tal apresentação desempenha um importante papel em um dos últimos livros do filósofo italiano, Il Regno $e$ la Gloria, na medida em que permite pensar o poder não apenas como tentativa de criação de ordem, mas ainda mais como governo, administração dos acontecimentos.
} 
Compreendendo, dessa mesma maneira, que um possível pensamento ético da vida não tem a necessidade de determinar uma essência ou uma finalidade para o vivente $^{3}$, antes de mais nada, Lóri nos coloca diante de um ser-dito. Ao rostificar os corpos em uma atividade de abstração e sobrecodificação, uma esfera de poder também opera sobre o ser-na-linguagem ao dizer desse ou daquele vivente "é um homem", “é um judeu”, “é um louco”. Faz-se isso na medida em que o destinatário das práticas é um lugar de operações capaz de ser constantemente rearticulado e dividido - "os indivíduos tornaram-se 'dividuais', divisíveis, e as massas tornaram-se amostras, dados, mercados ou 'bancos"” (DELEUZE, 2006a, p. 222), conforme apresentou Gilles Deleuze. Daí que se possa pensar mais na administração gloriosa das diversas qualificações prováveis aos viventes do que na assunção de uma única identidade a ser proclamada e salva. Mas justamente porque já não se trata de operar sobre um ser cuja substância pode ser revelada e comprovada, senão sobre um ser-dito, Agamben percebe uma maneira de usar esta condição como contra-dispositivo de poder:

Non l'esser-rosso, ma l'esser-detto-rosso; non l'esser-Jakob, ma l'esser-detto-Jakob definisce l'esempio. Di qui la sua ambiguità, non appena si decida di prenderlo veramente sul serio. L'esser-detto - la proprietà che fonda tutte le possibili appartenenze (l'esser-detto italiano, cane, comunista) - è, infatti, anche cio che può revocarle tutte radicalmente in questione (AGAMBEN, 2007, p. 14).

A literatura aí exerce um papel exemplar. Antes de cantar as constituições de uma realidade re-apresentável na ordem do dizível, a literatura pode de-lirar ${ }^{4}$. E, a despeito da inexorabilidade do princípio da razão suficiente, ela pode se voltar para os incompossíveis que restam virtuais na pirâmide das possibilidades tal qual imaginada pelo filósofo Leibniz, no século XVIII. Assim, não sendo determinante apenas a consciência de Lóri, mas ainda mais o seu ser-na-linguagem, ela pode desempenhar um papel de ajudante ${ }^{5}$ no pensamento de $u m a$ vida..${ }^{6}$ para além da identidade capturada e

\footnotetext{
3 "Il fatto da cui deve partire ogni discorso sull'etica è che l'uomo non è né ha da essere o da realizzare alcuna essenza, alcuna vocazione storica o spirituale, alcun destino biologico. Solo per questo qualcosa come un'etica può esistere: poiché è chiaro che se l'uomo fosse o avesse da essere questa o quella sostanza, questo o quel destino, non vi sarebbe alcuna esperienza etica possibile - vi sarebbero solo compiti da realizzare" (AGAMBEN, 2007a, p. 39).

${ }^{4}$ Conforme dizia Gilles Deleuze em A literatura e a vida, a literatura é um delírio, na medida em que pode "pôr em evidência no delírio essa criação de uma saúde, ou essa invenção de um povo, isto é, uma possibilidade de vida. Escrever por esse povo que falta... ('por' significa 'em intenção de' e não 'em lugar de')" (DELEUZE, 2006b, p. 15).

5 "Gli aiutanti sono i nostri desideri inesauditi, quelli che non confessiamo nemmeno a noi stessi, che nel giorno del giudizio ci verranno incontro sorridendo come Arturo e Geremia. Quel giorno, qualcuno ci
} 
aberta à comunidade que nunca cessa de vir. Nesse sentido, o rosto de Lóri, soterrado ou não pela maquiagem, também

è l'essere irreparabilmente esposto dell'uomo e, insieme, il suo restare nascosto proprio in quest'apertura. E il volto è il luogo della comunità, l'unica città possibile. Poiché ciò che, in ogni singolo, apre al politico, è la tragicommedia della verità in cui egli cade già sempre e di cui deve venire a capo (AGAMBEN, 1996, p. 74).

A revelação do rosto, conforme prossegue dizendo Agamben, é a revelação da linguagem, mas já não se trata da possibilidade de dizer a verdade sobre os estados de alma ou de fato, uma realidade. Essa revelação é somente abertura e comunicabilidade, ou seja, o lugar onde se dá a paixão da linguagem (AGAMBEN, 1996, pp. 74-75). Para Agamben, isso significa inclusive que o rosto desempenha um ponto de indiferença em relação a todas as propriedades determináveis:

Il mio volto è il mio fuori: un punto di indifferenza rispetto a tutte le mie proprietà, rispetto a ciò che è próprio e a ciò che è comune, a ciò che è interno e a ciò che è esterno. Nel volto, io sto con tutte le mie proprietà (il mio essere bruno, alto, pallido, orgoglioso, emotivo...), ma senza che nessuna di esse mi identifichi o mi appartenga essenzialmente. Esso è la soglia di de-propriazione e di deidentificazione di tutti i modi e di tutte le qualità, nella quale soltanto essi diventano puramente comunicabili (AGAMBEN, 1996, p. 80).

Assim, se o experimento de Descartes ao apresentar um olho que observa a própria visão, nas palavras de Agamben, desempenha uma irônica duplicação que assume um aspecto teatral, o rosto não serviria para revelar a presença da substancialidade de um sujeito pensante. Antes, o rosto estaria relacionado a algo que poderia receber o nome de maneira:

La maniera non è, cioè, né genere né individuo: è un esemplare, cioè, una singolarità qualunque [...] l'essere nella sua sorgività. Questo non

sconterà i nostri rossori come cambiali per il paradiso. Regnare non significa esaudire. Sginifica che l'inesaudito è ciò che rimane" (AGAMBEN, 2005c, p. 37).

${ }^{6}$ No texto A imanência: uma vida..., publicado por Deleuze, poucos meses antes de morrer, no número 47 da revista Philosophe, em 1995, o filósofo nos diz que: "Na ausência de consciência, o campo transcendental, escapando de toda transcendência tanto do sujeito quanto do objeto, definir-se-á como um puro plano de imanência. A imanência absoluta é nela mesma: ela não está em alguma coisa, dentro de alguma coisa, ela não depende de um objeto nem pertence a um sujeito [...] Dir-se-á que a pura imanência é UMA VIDA, nada mais. Ela não é imanência à vida, mas o imanente que não é imanente a nada específico é ele mesmo uma vida. Uma vida é a imanência da imanência, a imanência absoluta: ela é potência e beatitude completas" (DELEUZE, 2004, pp. 160-161). 
è, secondo la scissione che domina l'ontologia occidentale, né un'essenza, né un'esistenza, ma una maniera sorgiva; non un essere che è in questo o quel modo, ma un essere che è $i l$ suo modo di essere $\mathrm{e}$, pertanto, pur restando singolare e non indifferente, è multiplo e vale per tutti [...] L'essere che non resta sotto se stesso, che non si presuppone a sé come un'essenza nascosta, che il caso o il destino spingerebbero poi nel supplizio delle qualificazioni, ma si espone in esse, è senza residui il suo così, un tale essere non è accidentale né necessario, ma è, per così dire, continuamente generato dalla propria maniera (AGAMBEN, 2007, pp. 27-28).

Dizendo que essa maniera sorgiva é o lugar da singularidade qualquer e o seu principium individuationis, o filósofo italiano não trata da propriedade de uma maneira como sendo a capacidade de determinar e identificar o ser nos termos de uma essência. Pelo contrário, a maneira seria uma impropriedade, "questa improprietà è assunta e appropriata come il suo unico essere [...] L'improprietà che esponiamo come il nostro essere proprio, la maniera, che usiamo, ci genera, è la nostra seconda, più felice natura" (AGAMBEN, 1996, p. 29). Assim, sem deixar-se afogar pela narcísica e ludibriante completude de si, torna-se possível pensar uma vida... enquanto imanência da imanência. Aí os atos já não se resumem em um simples e acachapante cumprimento de mandatos, uma vez que conservam em seu movimento de translação a possibilidade da própria privação, a possibilidade de não se concretizarem - com paixão ${ }^{7}$. Trata-se,

portanto, de "uma vida que está por todos os lugares, por todos os momentos que atravessam este ou aquele sujeito vivo e que medem tais objetos vividos: vida imanente trazendo os acontecimentos ou singularidades que apenas se atualizam nos sujeitos e nos objetos" (DELEUZE, 2004, p. 162).

\section{REFERÊNCIAS}

AGAMBEN, Giorgio. "Il volto". In: . Mezzi senza fine. Note sulla politica. Torino: Bollati Boringhieri, 1996, pp. 74-80. . Quel che resta di Auschwitz. Torino: Bollati Boringhieri, 1998. . Homo sacer. O poder soberano e a vida nua. Tradução de Henrique Burigo. Belo Horizonte: Editora da UFMG, 2002a.

\footnotetext{
7 Cf. AGAMBEN, Giorgio. "La potenza del pensiero". In: La potenza del pensiero. Saggi e conferenze. Macerata: Quodlibet, 2005a, pp. 285-286.
} 
. "Idea del potere”. In: __. Idea della prosa. Macerata: Quodlibet, 2002b, pp. 51-52.

. Estado de exceção. Tradução de Iraci D. Poleti. São Paulo:

Boitempo, 2004.

. La potenza del pensiero. Saggi e conferenze. Vicenza: Neri

Pozza, 2005a.

. “O que é um dispositivo?". Tradução de Nilcéia Valdati. In: $A$ Exceção e o Excesso - Revista Outra Travessia (Curso de Pós-graduação em Literatura da Universidade Federal de Santa Catarina), $n^{\circ} 5$, Florianópolis, $2^{\circ}$ semestre de 2005b, pp. 09-16.

. “Gli aiutanti”. In: _. . Profanazioni. Roma: Edizioni nottetempo,

2005c, pp. 31-38.

. La comunità che viene. Torino: Bollati Boringhieri, 2007a.

. Il Regno e la Gloria. Per una genealogia teologica dell'economia

e del governo. Vicenza: Neri Pozza, 2007b.

SLOTERDIJK, Peter. Regras para o parque humano. Tradução de José Oscar de Almeida Marques. São Paulo: Estação Liberdade, 2000.

DELEUZE, Gilles; GUATTARI, Félix. "Ano zero - Rostidade”. In: . Mil Platôs 3 .

Tradução de Ana Lúcia de Oliveira e Lúcia Cláudia Leão. São Paulo: Editora 34, 2007, pp. 31-62.

DELEUZE, Gilles. “A imanência: uma vida...”. Tradução de Alberto Pucheu e Caio Meira. In: Terceira Margem. Revista do Programa de Pós-Gradução em Ciência da Literatura. Universidade Federal do Rio de Janeiro, Centro de Letras e Artes, Faculdade de Letras, Pós Graduação, Ano IX, nº 11, 2004, pp. 160-164.

DELEUZE, Gilles. "Post-scriptum sobre as sociedades de controle". In: Conversações. Tradução de Peter Pál Pelbart. São Paulo: Editora 34, 2006a, pp. 219226.

. "A literatura e a vida". In: _. Crítica e clínica. Tradução de

Peter Pál Pelbart. São Paulo: Editora 34, 2006b, pp. 11-16.

FOUCAULT, Michel. Seguridad, territorio, población. Curso em el Collège de France (1977-1978). Tradução para o espanhol de Horacio Pons. Buenos Aires: Fondo de Cultura Económica, 2006.

LISPECTOR, Clarice. Uma aprendizagem ou o livro dos prazeres. Rio de Janeiro: Rocco, 1998. 
NANCY, Jean-Luc. La creazione del mondo o la mondializzazione. Tradução para o italiano de Davide Tarizzo. Torino: Einaudi, 2003.

SCHMITT, Carl. Teologia Política. Tradução de Elisette Antoniuk. Belo Horizonte: Del Rey, 2006. 